\title{
BIOLOGICAL ACTIVITIES OF DIFFERENT EXTRACTS FROM ALLIUM URSINUM LEAVES
}

\author{
MILOS Z. KRIVOKAPIC ${ }^{1}$, VLADIMIR LJ. JAKOVLJEVIC ${ }^{2,3}$, MIROSLAV M. SOVRLIC $^{4}$, \\ JOVANA V. BRADIC ${ }^{4}$, ANICA M. PETKOVIC ${ }^{4}$, IVANA D. RADOJEVIC ${ }^{5}$, \\ SNEZANA R. BRANKOVIC ${ }^{5}$, LJILJANA R. COMIC ${ }^{5}$, MARIJANA M. ANDJIC ${ }^{4}$, \\ ALEKSANDAR G. KOCOVIC ${ }^{4}$ and MARINA T. TOMOVIC ${ }^{4 *}$
}

'Faculty of Medicine, University of Montenegro, Krusevac, 81000 Podgorica, Montenegro

${ }^{2}$ Department of Physiology, Faculty of Medical Sciences, University of Kragujevac, 69 Svetozara Markovica St., 34000 Kragujevac, Serbia

${ }^{3}$ Department of Human Pathology, Sechenov First Moscow State Medical University, 8 Trubetskaya Street St., 119991 Moscow, Russia

${ }^{4}$ Faculty of Medical Sciences, Department of Pharmacy, University of Kragujevac, 69 Svetozara Markovica St., 34000 Kragujevac, Serbia

${ }^{5}$ Department of Biology and Ecology, Faculty of Science, University of Kragujevac,

12 Radoja Domanovica St., 34000 Kragujevac, Serbia

\begin{abstract}
The aim of our study was to evaluate and compare the antioxidant and antimicrobial activity of aqueous, methanol and chloroform extracts of leaves of Allium ursinum (A. ursinum). Total phenol (TPC) and flavonoid (TFC) content in extracts and antioxidant activity using DPPH (1,1- diphenyl-2-picrylhydrazyl) assay were determined spectrophotometrically. In vitro antimicrobial activity was tested by the microdilution method. The highest TPC and TFC were observed for chloroform extract. The extracts showed different degrees of antimicrobial activity. The intensity of antimicrobial action varied depending on the group of microorganisms and the type of extracts. Our results demonstrated a rational basis for the traditional uses of A. ursinum in alleviation of oxidative stress and against various pathogenic microorganisms.
\end{abstract}

Keywords: Allium ursinum, antimicrobial activity, antioxidant activity

Allium ursinum L. (A. ursinum, family Amaryllidaceae), better known under the name of wild garlic, ramson or bear's garlic is a perennial herbaceous plant. It naturally grows in fens and marshes of Europe and Asia (1-3). Increasingly, popular in European kitchen A. ursinum can be used as a salad, spice or vegetable since all parts of the plant are edible. Throughout history leaves, bulbs and the aerial part of this plant species have been used in traditional medicine as therapeutic and prophylactic agents (4-6).

Numerous biologically active compounds enable this plant species to be implemented in the healing of various conditions for years. The most common are sulfur compounds which are considered to largely contribute to the pharmacological activity and from which originates a characteristic smell and taste (7). In addition to a significant presence of phenols, flavonoids, there are in a lesser extent other steroidal glycosides, amino acids, fatty acids, lecithin, essential oil $(4,8,9)$. The aforementioned bioactive compounds can be exploited and used in the form of various extracts. Experimental investigations indicate the efficiency of the application A. ursinum in prevention and treatment of many diseases such as cardiovascular diseases, cancer, obesity, diabetes, disorders of the gastrointestinal tract, elevated cholesterol level, as well as the inflammatory diseases (10-14).

It's been known that the applied extraction method and extraction solvent may substantially affect the quality and concentration of targeted com-

* Corresponding author: e-mail: marinapop@gmail.com 
pounds, thus affecting the overall biological effects of the obtained extract. Antimicrobial and antioxidant effects of $A$. ursinum extracts have been demonstrated, however, the information in this field is still lacking. Moreover, the true impact of solvents of different polarity on the potential of A. ursinum extracts against different microorganisms and oxidative stress has still to be understood (15-17). Extraction solvent should be selected based on the compounds targeted by the process, based on its selectivity, safety, cost, and availability $(18,19)$.

Therefore the aim of our study was to evaluate and compare the antioxidant and antimicrobial activity of aqueous, methanol and chloroform extract of A. ursinum leaves.

\section{MATERIALS AND METHODS}

\section{Plant material and extract preparation}

Fresh A. ursinum L. leaves ( $25 \mathrm{~g})$ were collected in May from mountain Bukulja $\left(44^{\circ} 17^{\prime} 55 \mathrm{~N}\right.$; $20^{\circ} 31^{\prime} 45 \mathrm{E}$ ). All plant samples were free of external damages, hand-selected, and chopped before analysis. Identification of plant material was performed at the Department of Biology, Faculty of Science in Kragujevac and botanical garden of Department of Biology, Faculty of Natural Sciences, University of Belgrade. Pulverized plant material was extracted with an appropriate solvent (water, methanol and chloroform; $500 \mathrm{~mL}$ ) by heat reflux extraction $(2 \mathrm{~h})$. The reflux extraction involves mixing plant material with a suitable solvent in a ratio of $1: 20$ to the boiling temperature of the solvent. The thusobtained extracts were evaporated under reduced pressure to constant weight. All dried extracts were weighed to determine the extraction yield and kept at $4^{\circ} \mathrm{C}$ prior to experimental studies (20). The yield of extracts: water, methanol and chloroform were $4.15 \mathrm{~g}, 4.20 \mathrm{~g}$ and $4.27 \mathrm{~g}$ respectively.

\section{Chemicals}

1,1-Diphenyl-2-picryl-hydrazyl-hydrate (DPPH), Folin-Ciocalteu reagent, $( \pm)$-catechin, were purchased from Sigma (Sigma- Aldrich GmbH, Sternheim, Germany). Gallic acid was purchased from Sigma (Sigma, St. Luis, 91 MO, USA). All other chemicals and reagents were of analytical reagent grade.

\section{Determination of the total phenolic (TPC) con- tent \\ Determination of the total phenols was per-} formed by the previously reported method (21). The total phenol value was expressed as $\mathrm{mg}$ of gallic acid equivalents (GAE) per gram of dry weight (dw).

\section{Determination of the total flavonoid (TFC) con- tent}

The content of flavonoids was calculated by aluminum chloride colorimetric method (21). Total flavonoid content was expressed as mg of quercetin equivalents $(\mathrm{QE})$ per $\mathrm{g}$ of $\mathrm{dw}$.

\section{Analysis of individual phenol compounds (HPLC-MS/MS)}

Extracts were diluted with $50 \%$ methanol to obtain three concentrations of 20.0, 2.0 and 0.2 $\mathrm{mg} / \mathrm{mL}$. Fifteen working standards, ranging from $1.53 \mathrm{ng} / \mathrm{mL}$ to $25.0 \cdot 10^{3} \mathrm{ng} / \mathrm{mL}$, were prepared by serial $1: 1$ dilutions of a standard mixture with a mixture of distilled water and methanol (1:1). Samples and standards were analyzed using Series high-performance liquid chromatograph (Agilent Technologies 1200) coupled with Triple Quad tandem mass spectrometer with electrospray ion source (Agilent Technologies 6410A).

Five microlitres were injected into the system, and compounds were separated on Zorbax Eclipse XDB-C18 $(50 \mathrm{~mm} \times 4.6 \mathrm{~mm}, 1.8 \mu \mathrm{m})$ rapid resolution column held at $50^{\circ} \mathrm{C}$. Mobile phase consisting of $0.05 \%$ aqueous formic acid (A) and methanol (B) was delivered at flow rate of $1 \mathrm{~mL} / \mathrm{min}$ in gradient mode $(0 \min 30 \%$ B, 6 min $70 \%$ B, 9 min $100 \%$ B, $12 \mathrm{~min} 100 \% \mathrm{~B}$, re-equilibration time $3 \mathrm{~min}$ ). Eluted components were detected by MS, using the ion source parameters as follows: nebulization gas (N2) pressure 50 psi, drying gas (N2) flow $10 \mathrm{~L} / \mathrm{min}$ and temperature $350^{\circ} \mathrm{C}$, capillary voltage $4 \mathrm{kV}$, negative polarity. Data were acquired in dynamic SRM mode. For all the compounds, peak areas were determined using Agilent MassHunter Workstation Software - Qualitative Analysis (ver. B.03.01). Calibration curves were plotted and samples' concentrations calculated using the Microsoft Excel software.

\section{Evaluation of antioxidant activity}

Antioxidant potential of extracts was determined using previously adapted assays for 96-well microplates related to free radical scavenging ability towards DPPH (1,1-diphenyl-2-picrylhydrazyl) (22). Ten microliters of each A. ursinum extract in series of concentrations $(0.125-16 \mathrm{mg} / \mathrm{mL})$, were added to $100 \mu \mathrm{L}$ of $90 \mu \mathrm{mol} / \mathrm{L}$ DPPH solution in methanol, and the mixture was diluted with additional $190 \mu \mathrm{L}$ of methanol. In controls, the $10 \mu \mathrm{L}$ of the sample was substituted with water (for $A$. 
ursinum aqueous extract), $50 \%$ methanol (for $A$. ursinum methanol extract) or DMSO (for A. ursinum chloroform extract). Measurements of absorbance were read at $515 \mathrm{~nm}$ after $1 \mathrm{~h}$. All samples and the control were made in triplicate. The percentage of inhibition achieved by different concentrations of samples was calculated by using the following equation: $\mathrm{I}(\%)=\left(\mathrm{A}_{0}-\mathrm{A}\right) / \mathrm{A}_{0} \times 100$, where $\mathrm{A}_{0}$ was the absorbance of the control reaction and $\mathrm{A}$ was the absorbance of the examined samples, both corrected for the value of the corresponding blank probes. Corresponding inhibition-concentration curves were drawn using Origin software, version 8.0 and $\mathrm{IC}_{50}$ values (concentration of extract that inhibited $\mathrm{DPPH}^{\bullet}$ formation by 50\%) were determined. For each assay final result was expressed as the mean \pm standard deviation (SD) of three measurements.

\section{In vitro antimicrobial assay Test substances}

The tested extracts were dissolved in DMSO and then diluted into a nutrient liquid medium to achieve a concentration of $10 \%$. Dimethyl sulfoxide (DMSO) was purchased from Acros Organics (NewJersey, USA). Resazurin was obtained from Alfa Aesar GmbH \& Co. (KG, Karlsruhe, Germany). An antibiotic, doxycycline (Galenika A.D., Belgrade), was dissolved in a nutrient liquid medium, a Mueller-Hinton broth (Torlak, Belgrade), while antimycotic, fluconazole (Pfizer Inc., USA) was dissolved in Sabouraud dextrose broth (Torlak, Belgrade).

\section{Test microorganisms}

The antimicrobial activity of A. ursinum extracts was tested against 20 microorganisms. The experiment involved 10 strains of pathogenic bacteria, including six standard strains and four clinical isolates. Also, seven mold species and three yeast species were tested, including five standard strains and five isolates from food and nature. All clinical isolates were a generous gift from the Institute of Public Health, Kragujevac. The other microorganisms were provided from the collection held by the Microbiology Laboratory Faculty of Science, University of Kragujevac.

\section{Suspension preparation}

The bacterial suspensions were prepared by the direct colony method. The turbidity of the initial suspension was adjusted using a densitometer (DEN-1, BioSan, Latvia). When adjusted to the turbidity of the 0.5 McFarland's standard (23) the bacteria suspension contains about $10^{8}$ colony forming units $(\mathrm{CFU}) / \mathrm{mL}$ and the suspension of yeast contains $10^{6} \mathrm{CFU} / \mathrm{mL}$. Ten-fold dilutions of the initial suspension were additionally prepared into sterile $0.85 \%$ saline. Bacterial inoculi were obtained from bacterial cultures incubated for $24 \mathrm{~h}$ at $37^{\circ} \mathrm{C}$ on Müller-Hinton agar substrate and brought up by dilution according to the $0.5 \mathrm{McF}$ arland standard to approximately $10^{6} \mathrm{CFU} / \mathrm{mL}$. Suspensions of fungal spores were prepared from fresh mature (3-to 7-dayold) cultures that grew at $30^{\circ} \mathrm{C}$ on PDA (Potato Dextrose Agar). Spores were rinsed with sterile distilled water, used to determine turbidity spectrophotometrically at $530 \mathrm{~nm}$, and then further diluted to approximately $10^{6} \mathrm{CFU} / \mathrm{mL}$ according to the procedure recommended by NCCLS (24).

\section{Microdilution method}

Antimicrobial activity was tested by determining the minimum inhibitory concentrations (MIC) and minimum microbicidal concentration (MMC) using the microdilution plate method with resazurin (25). The 96-well plates were prepared by dispensing $100 \mu \mathrm{L}$ of nutrient broth, Mueller-Hinton broth for bacteria and Sabouraud dextrose broth for fungi, into each well. A $100 \mu \mathrm{L}$ aliquot from the stock solution of the tested extracts (with a concentration of 10 $\mathrm{mg} / \mathrm{mL}$ ) was added into the first row of the plate. Then, twofold serial dilutions were performed by using a multichannel pipette. The obtained concentration range was from 5 to $0.078 \mathrm{mg} / \mathrm{mL}$. The method is described in detail in the reported paper (26).

Doxycycline and fluconazole were used as a positive control. 10\% DMSO (as solvent control test) was recorded not to inhibit the growth of microorganisms. Each test included growth control and sterility control. All the tests were performed in duplicate and the MICs were constant. Minimum microbicidal concentrations were determined by plating $10 \mu \mathrm{L}$ of samples from wells where no indicator color change or no mycelia growth was recorded on nutrient agar medium. At the end of the incubation period, the lowest concentration with no growth (no colony) was defined as the minimum microbicidal concentration.

\section{Statistical analysis}

IBM SPSS Statistics 20.0 for Windows was used for statistical analysis of the antioxidant activity of extracts. Descriptive statistics were used to calculate the arithmetic mean with dispersion measures (standard deviation SD and standard error SE). Data were expressed as mean \pm standard error (SE). Shapiro-Wilk test was used to check the distribution 
of data. Data were analyzed using a one-way analysis of variance (ANOVA) and the post hoc Bonferroni test for multiple comparisons. Values of $\mathrm{p}<0.05$ were considered to be statistically significant, while values of $\mathrm{p}<0.01$ were considered to be highly significant.

\section{RESULTS}

Determination of the total phenolic (TPC) and total flavonoid content (TFC)

Quantitative phytochemical analysis of major compounds found in extracts from A. ursinum leaves is presented in Table 1. The highest TPC was observed in the chloroform extract $(60.47 \pm 5.95 \mathrm{mg}$ gallic acid equivalents/g of dw) while the lowest in the methanol extract $(33.29 \pm 3.13 \mathrm{mg}$ gallic acid equivalents/g of $\mathrm{dw}$ ). The chloroform extract also shows the highest TFC value $(34.76 \pm 1.31 \mathrm{mg}$ quercetin equivalents/g of $\mathrm{dw}$ ) compared to methanol ( $6.86 \pm 0.10 \mathrm{mg}$ quercetin equivalents/g of $\mathrm{dw})$ and aqueous $(3.34 \pm 0.05 \mathrm{mg}$ quercetin equivalents/g of dw) extract.

\section{Analysis of individual phenol compounds (HPLC-MS/MS)}

Results of the HPLC-MS / MS analysis of these extracts indicate the presence of a number of different bioactive compounds presented in Table 2. Major phenolics present in all extracts are kaempferol 3-O-Gl, kaemferol and ferulic acid.

\section{Antioxidant activity}

DPPH assay applied in our study is one of the most commonly used methods for determining antioxidant capacity in vitro (22). Our results are presented in Table 3. These results indicate that the highest DPPH activity and lowest IC50, which corresponds to the strongest antioxidant activity, was found in the case of methanol extract. On the con-

Table 1. Total phenol and flavonoid content of A. ursinum extracts.

\begin{tabular}{|l|c|c|c|}
\hline & Aqueous extract & Methanol extract & Chloroform extract \\
\hline $\begin{array}{l}\text { Total phenolics } \\
(\mathrm{mg} \text { gallic acid equivalents/g of dw) }\end{array}$ & $34.55 \pm 3.49$ & $33.29 \pm 3.13$ & $60.47 \pm 5.95$ aa,bb \\
\hline $\begin{array}{l}\text { Total flavonoids } \\
(\mathrm{mg} \text { quercetin equivalents/g of dw) }\end{array}$ & $3.34 \pm 0.05$ & $6.86 \pm 0.10 \mathrm{a}$ & $34.76 \pm 1.31$ aa,bb \\
\hline
\end{tabular}

Values are presented as mean value \pm SD of three measurements; ${ }^{\text {aa }}$ statistical significance at the level of $\mathrm{p}<0.01$ in incomparison to aqueous extract. ${ }^{\text {bb }}$ statistical significance at the level of $\mathrm{p}<0.01$ in comparison to methanol extract.

Table 2. Quantitative and qualitative analysis of individual compounds found in A. ursinum extracts expressed as $\mu \mathrm{g} / \mathrm{g}$ of dry extract.

\begin{tabular}{|l|c|c|c|}
\hline & $\begin{array}{c}\text { A. ursinum } \\
\text { aqueous extract }\end{array}$ & $\begin{array}{c}\text { A. ursinum } \\
\text { methanol extract }\end{array}$ & $\begin{array}{c}\text { A. ursinum } \\
\text { chloroform extract }\end{array}$ \\
\hline p-coumaric acid & $18.79 \pm 1.69$ & $9.92 \pm 0.89$ & $2.22 \pm 0.20$ \\
\hline Ferulic acid & $12.59 \pm 1.26$ & $7.55 \pm 0.76$ & $33.88 \pm 3.9$ \\
\hline Kaempferol & $10.20 \pm 0.71$ & $6.75 \pm 0.47$ & $38.70 \pm 2.71$ \\
\hline Kaempferol 3-O-Glc & $10 \pm 42$ & $376 \pm 15$ & $10 \pm 0.4$ \\
\hline Ursolic acid & $1.13 \pm 0.01$ & $1.57 \pm 0.01$ & $12.80 \pm 0.08$ \\
\hline
\end{tabular}

Table 3. DPPH free radical scavenging activity of the A. ursinum extracts (AU).

\begin{tabular}{|l|c|c|c|}
\hline & Aqueous extract & Methanol extract & Chloroform extract \\
\hline $\begin{array}{l}\mathrm{DPPH} \\
\text { IC } C_{50} \text { values }(\mu \mathrm{g} / \mathrm{mL})^{\S}\end{array}$ & $154.25 \pm 3.50$ & $111.04 \pm 7.69^{\text {a }}$ & $391.79 \pm 33.01^{\text {aa,bb }}$ \\
\hline
\end{tabular}

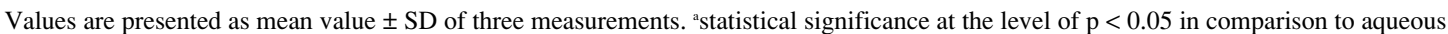
extract; aastatistical significance at the level of $\mathrm{p}<0.01$ in comparison to aqueous extract; ${ }^{\text {bb }}$ statistical significance at the level of $\mathrm{p}<0.01$ in comparison to methanol extract. 
Table 4. Antibacterial activity of aqueous, methanol and chloroform extracts of A. ursinum.

\begin{tabular}{|l|c|c|c|c|c|c|c|c|}
\hline \multicolumn{1}{|c|}{ Type of extracts } & \multicolumn{2}{c|}{$\begin{array}{c}\text { Aqueous } \\
\text { extract }\end{array}$} & \multicolumn{2}{c|}{$\begin{array}{c}\text { Methanol } \\
\text { extract }\end{array}$} & \multicolumn{2}{c|}{$\begin{array}{c}\text { Chloroform } \\
\text { extract }\end{array}$} & \multicolumn{2}{c|}{ Doxycycline } \\
\hline \multicolumn{1}{|c|}{ Species } & MIC & MMC & MIC & MMC & MIC & MMC & MIC & MMC \\
\hline Staphylococcus aureus & 5 & 5 & 5 & 5 & 2.5 & 2.5 & 0.448 & 7.81 \\
\hline S. aureus ATCC 25923 & $>5$ & $>5$ & $>5$ & $>5$ & 5 & $>5$ & 0.22 & 3.75 \\
\hline Bacillus cereus & 5 & $>5$ & 5 & $>5$ & 2.5 & 2.5 & 0.977 & 7.81 \\
\hline Bacillus subtilis & $>5$ & $>5$ & $>5$ & $>5$ & 5 & 5 & 0.112 & 1.953 \\
\hline B. subtilis ATCC 6633 & 2.5 & 5 & 1.25 & 2.5 & 0.313 & 0.625 & 1.953 & 31.25 \\
\hline Escherichia coli ATCC 25922 & $>5$ & $>5$ & $>5$ & $>5$ & $>5$ & $>5$ & 15.63 & 31.25 \\
\hline Proteus mirabilis ATCC 12453 & $>5$ & $>5$ & $>5$ & $>5$ & 5 & $>5$ & 15.63 & 62.5 \\
\hline Pseudomonas aeruginosa ATCC 27853 & $>5$ & $>5$ & $>5$ & $>5$ & $>5$ & $>5$ & 62.5 & 125 \\
\hline Cronobacter sakazakii ATCC 29544 & $>5$ & $>5$ & $>5$ & $>5$ & $>5$ & $>5$ & $/$ & $/$ \\
\hline Salmonella enterica & $>5$ & $>5$ & $>5$ & $>5$ & $>5$ & $>5$ & 15.63 & 31.25 \\
\hline
\end{tabular}

${ }^{1} \mathrm{MIC}$ and ${ }^{2} \mathrm{MMC}$ values - means inhibitory activity and microbicidal activity; for plant extracts are given as $\mathrm{mg} / \mathrm{mL}$; for antibiotic are given as $\mu \mathrm{g} / \mathrm{mL}$.

Table 5. Antifungal activity of aqueous, methanol and chloroform extracts of A. ursinum.

\begin{tabular}{|l|c|c|c|c|c|c|c|c|}
\hline $\begin{array}{c}\text { Type } \\
\text { of extracts }\end{array}$ & \multicolumn{2}{|c|}{$\begin{array}{c}\text { Aqueous } \\
\text { extract }\end{array}$} & \multicolumn{2}{c|}{$\begin{array}{c}\text { Methanol } \\
\text { extract }\end{array}$} & \multicolumn{2}{c|}{$\begin{array}{c}\text { Chloroform } \\
\text { extract }\end{array}$} & \multicolumn{2}{c|}{ Fluconazole } \\
\hline \multicolumn{1}{|c|}{ Species } & MIC & MMC & MIC & MMC & MIC & MMC & MIC & MMC \\
\hline Rhodotorula mucilaginosa & 5 & 5 & 2.5 & 5 & $>5$ & $>5$ & 31.25 & 500 \\
\hline Saccharomyces boulardii & $>5$ & $>5$ & $>5$ & $>5$ & 0.625 & 5 & 7.81 & 31.25 \\
\hline Candida albicans ATCC 10231 & 5 & $>5$ & 5 & $>5$ & 5 & $>5$ & 31.25 & 62.5 \\
\hline Penicillium expansum & $>5$ & $>5$ & 5 & $>5$ & $>5$ & $>5$ & $/$ & $/$ \\
\hline P. chrysogenum & 5 & $>5$ & 5 & $>5$ & $>5$ & $>5$ & 1000 & 1000 \\
\hline P. italicum & 2.5 & $>5$ & 2.5 & $>5$ & 5 & $>5$ & 250 & 500 \\
\hline Trichoderma viridae ATCC 13233 & 5 & $>5$ & 5 & $>5$ & 2.5 & 5 & 500 & 1000 \\
\hline Aspergillus flavus ATCC 9170 & $>5$ & $>5$ & $>5$ & $>5$ & 0.625 & 2.5 & 500 & 500 \\
\hline A. fumigatus ATTC 204305 & $>5$ & $>5$ & 5 & $>5$ & 2.5 & 5 & 1000 & 1000 \\
\hline A. niger ATCC 16404 & 5 & $>5$ & 5 & $>5$ & 0.313 & 2.5 & 1000 & 1000 \\
\hline
\end{tabular}

${ }^{1} \mathrm{MIC}$ and ${ }^{2} \mathrm{MMC}$ values - means inhibitory activity and microbicidal activity; for plant extracts are given as $\mathrm{mg} / \mathrm{mL}$; for antimycotic are given as $\mu \mathrm{g} / \mathrm{mL}$.

trary, the minimum antioxidant potential was revealed for chloroform extract.

\section{In vitro antimicrobial activity}

The results of in vitro antimicrobial activity of extracts against 20 strains of bacteria and fungi, with control results, were determined by microdilution method. The results are presented in Tables 4 and 5 . It was observed that the growth of microorganisms was not inhibited by $10 \%$ DMSO. Generally, the extracts showed different degrees of antimicrobial activity. The intensity of antimicrobial action varied depending on the group of microorganism, and the type of extracts. MICs and MMCs values were in range from 0.313 to $>5 \mathrm{mg} / \mathrm{mL}$. Among the tested substances the most significant activity showed chloroform extract, both on Gram-positive bacteria and filamentous fungi. The same extract showed better antifungal activity than the positive control (MIC - $0.313 \mathrm{mg} / \mathrm{mL}$ on A. niger ATCC 16404). Among bacteria, B. subtilis ATCC 6633 showed the highest sensitivity to the tested extracts. The tested 
extracts showed the lowest antimicrobial activity on the Gram-negative bacteria (MICs were mostly $>5$ $\mathrm{mg} / \mathrm{mL})$.

\section{DISCUSSION AND CONCLUSION}

There is evidence suggesting that solvent polarity strongly affects the concentration of S-containing compounds and pharmacological activity of A. ursinum extract $(27,28)$. However, the difference between total phenol and flavonoid content as well as antimicrobial and antioxidant activity of water, methanol and chloroform extracts of $A$. ursinum has not been fully clarified so far. Previously conducted studies referring to phytochemical and pharmacological profile of $A$. ursinum were mostly oriented on the extraction of this plant species on room temperature, while we applied extraction under reflux for obtaining extract. Since storing of A. ursinum over time slightly induces a loss in sulfur-containing volatile bioactive molecules, but not in phenolic compounds, the findings of our research reflect the potential for using ramsons during the whole year, not only in blooming period. Therefore, we assessed total phenol and flavonoid concentration, anti-oxidant and antimicrobial potential of the aqueous, methanol and chloroform extracts derived from the leaves of this plant species using heat reflux extraction.

According to the literature data, the organosulfur compounds (OSCs) and non-volatile S-alk(en)yl cysteine sulfoxides (ACSO) are known to possess numerous bioactive properties characteristic for Allium genus. However, it's been found that these compounds are thermally labile and capable of undergoing heat-induced non-enzymatic transformations. Results of previous studies showed that prolonging the thermal treatment to 20 or $30 \mathrm{~min}$ decreased their concentrations of allyl polysulfides (29-31). The highest TPC and TFC in this investigation were observed in the chloroform extract. Previous research showed that methanolic extracts had a higher value of TPC compared to water, however, in our study, there was no difference between the TPC content of these two types of extracts (27). It has been previously noticed that locality from which plant material is collected affects the chemical composition and antioxidant activity of ethanolic extract of A. ursinum (32). However, extraction under reflux has an advantage toward ultrasonic extraction applied in that study, since degradation of some bioactive compounds might occur during sonication (33). Besides the method of extraction, our results strongly confirm that the extraction solvent affects the phenolic content. The amount of phenolic compounds in the extracts to a large extent beside the solvent depends on the polarity of the extraction mode (34). The important factor that affects the concentration of active components is harvest time (2, $35,36)$.

The polarity of the solvent used for extraction directly affects not only the quantity of TF but also the composition of flavonoids and other polyphenolic compounds (37). The solubility of biomolecules varies depending on the polarity of the solvent, thus explaining the different qualitative and quantitative composition of examined extracts. Factors that mostly affect the solubility of polyphenols are their molecular size, the presence and position of hydroxyl groups and the length of hydrocarbon chains (38).

In our study, we used DPPH method in order to determine the antioxidant effect of A. ursinum extracts. DPPH method is a useful and reliable tool for estimating free-radical scavenging activity of phenolic compounds (22). The highest activity was observed for methanol extract, followed by the aqueous extract. The high antioxidant potential of our extracts was partially influenced by the extraction on elevated temperature since it has been reported that an increase in extraction temperature leads to a decrease in IC50. Moreover, literature data suggest that alcoholic extracts possess better antioxidant activity compared to the aqueous ones (39). On the other hand, water extract was found to have higher DPPH radical scavenging activity than $70 \%$ ethanol extract, probably due to the presence of more polar (poly) phenolic compounds with stronger antioxidant activity (40). Interestingly A. ursinum water extract has an antioxidant capacity lasting for several hours. As such, after $24 \mathrm{~h}$, the antioxidant capacity of an A. ursinum extract prepared by homogenization of the bulbs in distilled water is decreased. Ramson's bulbs are a poor source of polyphenols and their antioxidant activity is associated with the presence of other compounds (41). Additionally, it has been suggested earlier that $80 \%$ methanol was more effective extraction solvent for A. ursinum in comparison to ethanol (42). According to the literature data, we may hypothesize that presence of flavonoid constituents mostly contribute to the antioxidative potential of $A$. ursinum extract (43). While a correlation between antioxidant activity and phenol content of A. ursinum has been suggested previously, our results indicate the highest phenol content of chloroform and antioxidant capacity of methanol extract (44). It is been proposed that all plant organs of Allium 
species exhibit antioxidant properties. Furthermore, it is well evidenced that the highest antioxidant activity of leaves of A. ursinum is a result of high antioxidant enzyme activities, involving catalase (CAT) and glutathione peroxidase (GPx). In fact ,CAT and GPX reduce $\mathrm{H}_{2} \mathrm{O}_{2}$ and other organic peroxides thus protecting cell proteins and membranes against oxidation (40). When an antioxidant finds itself in a complex environment it reacts depending on their chemical nature, which results in different numerical values of the results. The values obtained can be often in a weak correlation and therefore it is necessary to carry out more tests to be assessed with certainty antioxidant ability of the test substance or extract (40).

The intensity of antimicrobial action varied depending on the group of microorganism, and the type of extracts. Among the tested substances the most significant activity showed chloroform extract, both on Gram-positive bacteria and filamentous fungi. Our results are partially consistent with other studies. As well as our research the results of antimicrobial screening of the A. ursinum pressurized-liquid extract against the broad range tested microorganisms did not show any significant activity. Higher activities were obtained towards $S$. aureus and $A$. niger (36). Other studies showed that the antimicrobial effects of $A$. ursinum depend mostly on the pathogenic species and the type of plant extract (39-41). It was confirmed that both ethanolic and hydromethanolic extract of A. ursinum exhibited certain antioxidant and strong antimicrobial activity against $S$. enteritidis, E. coli, $P$. mirabilis and E. faecalis) (46).

Unlike our research, one study reported that the extracts from A. ursinum plants (obtained by the homogenization in distilled water), inhibited growth of Candida spp. cells at concentrations ranging from 0.5 to $4.0 \mathrm{mg} / \mathrm{mL}$, while that of adherent cells at concentrations ranging from 1.0 to $>4.0 \mathrm{mg} / \mathrm{mL}$, depending on the yeast and plant species (16). This discrepancy in findings might be explained by usage of different methods of extraction and consequently dissimilar chemical composition of the extract. In fact, in the previous studies, several sulfur compounds were isolated from extract and tested, however, we aimed to assess the antimicrobial potential of the whole A. ursinum extract containing a variety of bioactive flavonoids.

By studying the chemical composition of the tested extracts, the highest presentation of $\mathrm{p}$ coumaric acid, ferulic acid and kaempferol and its derivates is observed. Some research reveals that $\mathrm{p}$ coumaric acid showed antimicrobial effect only in cumulation. Low concentration of p-coumaric acid alone did not exert any zone of inhibition on microbial strains, but this compound in cumulation showed zone of inhibition on various microbial strains. Cumulative action of p-coumaric acid at 200 $\mu \mathrm{g}$ was very effective on Bacillus subtilis (47). In our research, the best antimicrobial activity of all extracts is at B. subtilis ATCC 6633 (MICs are $0.313-2.5 \mathrm{mg} / \mathrm{mL}$ ).

It was found that ferulic acid has antimicrobial activity with MIC/MBC of $100 / 2500 \mu \mathrm{g} / \mathrm{mL}$ for $E$. coli, $100 / 500 \mu \mathrm{g} / \mathrm{mL}$ P. aeruginosa, and 1100/5000 $\mu \mathrm{g} / \mathrm{mL}$ for $S$. aureus. Ferulic acid led to irreversible changes in membrane properties through hydrophobicity changes (37). The results of some research demonstrate that ferulic acid has moderate antimicrobial activity against Cronobacter sakazakii (MIC from 2.5 to $5.0 \mathrm{mg} / \mathrm{m}$ ). As with previous research, it exerts its antimicrobial action partly by through causing cell membrane dysfunction and changes in cellular morphology (49). The crude extracts of some plants have shown antimicrobial activity on the set of germs, with MIC values from 16 to 1024 $\mu \mathrm{g} / \mathrm{mL}$. At the same time, kaempferol rhamnoside derivatives isolated from the same extracts show antimicrobial activity with MIC values from 1 to $256 \mu \mathrm{g} / \mathrm{mL}(50)$.

The content of ferulic acid in water, methanol and chloroform extracts is $12.59 \pm 1.26 ; 7.55 \pm 0.76$ and $33.88 \pm 3.9$ in that order. The content of $\mathrm{p}$ coumaric acid is $18.79 \pm 1.69 ; 9.92 \pm 0.89$ and 2.22 \pm 0.20 whilst the content of kaempferol in these extracts is $10.20 \pm 0.7 ; 6.75 \pm 0.47 ; 38.70 \pm 2.71$. Our results are in correlation with the antimicrobial activity of these extracts. The highest contents of these components were observed in chloroform extract and accordingly the most significant antimicrobial activity showed chloroform extract, both on Gram-positive bacteria and filamentous fungi. There was no significant difference between water and methanol extracts in antimicrobial activity. Unlike our research, in the study which describes antimicrobial activity of methanol and water extract from Ramsons, methanol extract shows more inhibitory activity against microbes than water extract and for the antimicrobial activity of water extract higher concentration than for methanol extract is necessary (51).

Based on our results we may conclude that the highest DPPH activity which corresponds to the strongest antioxidant activity, was found in the case of methanol extract. On the contrary, the minimum antioxidant potential was revealed for chloroform extract. The extracts showed different degrees of 
antimicrobial activity. The intensity of antimicrobial action varied depending on the group of microorganism, and the type of extracts. The most significant activity showed chloroform extract, both on Gram-positive bacteria and filamentous fungi.

However, further investigations oriented on isolation and characterization of the present antioxidants and antimicrobial substances in various in vitro and in vivo tests are certainly necessary to fully clarify the effects of this plant species and underlying mechanism.

\section{Acknowledgment}

The authors would like to express gratitude to the Faculty of Medical Sciences, the University of Kragujevac for Grant No. JP 06/17 and Ministry of Education, Science of the Republic of Serbia (Grant No. 41010, 173032 and 175043).

\section{Conflict of interest}

The authors declare that they have no conflict of interest.

\section{REFERENCES}

1. Oborny B., Botta- Dukat Z., Rudolf., Morschhauser T.: Acta Bot. Hung. 53, 371 (2011).

2. Schmitt B., Schulz H., Storsberg J., Keusgen M.: J. Agric. Food Chem. 53, 7288 (2005).

3. Wu H., Dushenkov S., Ho C.T., Sang S.: Food Chem. 115, 592 (2009).

4. Sobolewska D., Podolak I., Makowska-Wąs J.: Phytochem. Rev. 14, 81 (2015).

5. Leporatti M.L., Ivancheva S.: J. Ethnopharmacol. 87, 123 (2003).

6. Oszmiański J., Kolniak-Ostek J., Wojdyło A.: J. Agric. Food Chem. 61, 176 (2013).

7. Block E., Birringer M., Jiang W., Nakahodo T., Thompson H.J., et al.: J. Agric. Food Chem. 49, 458 (2001).

8. Carotenuto A., De Feo V., Fattorusso E., Lanzotti V., Magno S., Ít al.: Phytochemistry 41, 531 (1996).

9. Xu X.Y., Song GQ., Yu YQ., Ma HY., Ma L., et al.: OncoTargets Ther. 6, 779 (2013).

10. Gorinstein S., Jastrzebski Z., Namiesnik J., Leontowicz H., Leontowicz M., et al.: Mol. Nutr. Food Res. 51, 1365 (2007).

11. Sabha D., Hiyasat B., Grötzinger K., Hennig L., Schlegel F., et al.: Pharmacology 89, 260 (2012).
12. Sengupta A., Ghosh S., Bhattacharjee S.: Asian Pac. J. Cancer Prev. 5, 237 (2004).

13. Kalayarasan S., Prabhu N., Sriram N., Manikandan R., Arumugam M., Sudhandiran G.: Eur. J. Pharmacol. 606, 162 (2009).

14. Hodge G., Hodge S., Han P.: Cytometry A 48, 209 (2002).

15. Hiyasat B., Sabha D., Grötzinger K., Kempfert J., Rauwald J. et al.: Pharmacology 83, 197 (2009).

16. Bagiu R., Vlaicu B., Butnariu M.: Int. J. Mol Sci. 13, 1426 (2012).

17. Stajner D., Popovic B.M., Canadanovic-Brunet J., Stajner M.: Fitoterapia 79, 303 (2008).

18. Khoddami A., Wilkes M.A., Roberts T.H.: Molecules 18, 2328 (2013).

19. Ramić M., Vidović S., Zeković Z., Vladić J., Cvejin A., et al.: Ultrason. Sonochem. 23, 360 (2015).

20. Hijazi A., Al Masri DS., Farhan H., Nasser M., Rammal H., et al.: JPCBS 3, 262 (2015).

21. Naðpal J., Lesjak M., Šibul S., Anačkov G.T., Četojević-Simin D., et al.: Food Chem. 192, 907 (2016).

22. Lesjak M.M., Beara I.N., Orčić D.Z., Knežević P.N., Simin N.D., et al.: J. Funct. Foods 7, 257 (2014).

23. Andrews J.: Antimicrob. Chemother 56, 60 (2005).

24. NCCLS (National Commitee for Clinical Laboratory Standards) Reference method for broth dilution antifungal susceptibility testing of conidium-forming filamentous fungi: Proposed Standard M38-P. NCCLS, Wayne, PA, USA (1998).

25. Sarker S., Nahar L., Kumarasamy Y.: Methods 42, 321 (2007).

26. Vasic M., Stefanovic D., Licina Z., Radojevic D., Comic R.: EXCLI J. 11, 208 (2012).

27. Sendl A., Elbl G., Steinke B., Redl K., Breu W., Wagner H.: Planta Med. 58, 1 (1992).

28. Sendl A., Wagner.: Planta Med. 56, 588 (1990).

29. Locatelli D.A., Altamirano J.C., González R.E., Camargo A.B.: J. Funct. Foods. 16, 1 (2015).

30. Locatelli D.A., Nazareno M.A., Fusari C.M., Camargo A.B.: Food Chem. 220, 219 (2017).

31. Tocmo R., Wu Y., Liang D., Fogliano V., et al.: Food Chem. 221, 1867 (2017).

32. Jovanova B., Kulevanova S., Kadifkova Panovska T.: Agric. Conspec. Sci. 84, 51 (2019).

33. Milic S, Stanojevic P., Rajkovic M.: Hem. Ind. 67, 89 (2013).

34. Moller S., Madsen L., Aaltonen T., Skibsted H.: Food Chem. 64, 215 (1999). 
35. Oszmiański J., Kolniak-Ostek J., Wojdyło A.: J. Agric. Food Chem. 176 (2013).

36. Mihaylova D., Lanteb A., Tinellob F., Krastanova A.: Nat. Prod. Res. 28, 2000 (2014).

37. Valdramidis V., Tiwari B., Cullen P., Kondjoyan A., Impe J.V.: Food Control. 22, 137 (2011).

38. Iloki-Assanga B., Lewis-Luján M., LaraEspinoza C.L., Gil-Salido A.A., FernandezAngulo D., et al.: BMC Res. Notes 8, 396 (2015).

39. Sapunjieva T., Alexieva I., Mihaylova D., Popova A.: BioSci. Biotech. 143 (2012).

40. Nikkhahi M., Souri E., Sarkhail P., Baeeri M., Mohammadhosseini N.: Acta Sci. Pol. Technol. Aliment. 17, 219 (2018).

41. Putnoky S., Cauniiand A., Butnariu M.: Chem. Cent. J. 7, 21 (2013).

42. Pejatović T., Samardžić D., Krivokapić S.: JMES 8, 1929 (2017).

43. Škrovánková S., Mlček J., Snopek L., Planetová T.: Potr. S. J. F. Sci. 12, 267 (2018).
44. Sobolewska D., Janeczko Z., Kisiel W., Podolak I., Galanty A., Trojanowska D.: Acta Pol. Pharm. 63, 219 (2006).

45. Ivanova A., Mikhova B., Najdenski H., Tsvetkova I., Kostova I.: Nat. Prod. Commun. 4, 1059 (2009).

46. Pavlović R., Veljković M., Stojanović M., Gočmanac-Ignjatović M., Mihailov-Krstev T., et al.: J. Pharm. Pharmacol. 69, 1208 (2017).

47. Naga Vamsi Krishna A., Nadeem M., Saradhi P., Mahendran B., Bharathi S.: J. Exp. Biol. 4, 40 (2014).

48. Borges A., Ferreira C., Saavedra M.J., Simőes M.: Microb. Drug Resist. 19, 256 (2013).

49. Shi C., Zhang X., Sun Y., Yang M., Song K., et al.: Foodborne Pathog. Dis. 13, 196 (2016).

50. Tatsimo S.J., Tamokou D., Havyarimana L., Csupor D., Forgo P., et al.: BMC Res. Notes 5, 158 (2012).

51. Synowiec A., Gniewosz M., Zieja I., Baczek K., Przybyl J.: Zeszyty Problemowe Postępów Nauk Rolniczych, 553 (2010) (in Polish).

(C) 2020 by Polish Pharmaceutical Society. This is an open access article under the CC BY NC license (c) (i) (8) (http://creativecommons.org/licenses/BY/4.0/). 